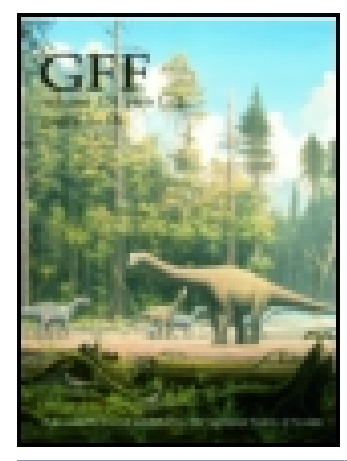

Geologiska Föreningen i Stockholm Förhandlingar

\title{
Om olika jordarters olika förmåga att upplösa benmjölet
}

\section{E. O. Arenander}

To cite this article: E. O. Arenander (1909) Om olika jordarters olika förmåga att upplösa benmjölet, Geologiska Föreningen i Stockholm Förhandlingar, 31:5, 398-402, DOI:

$\underline{10.1080 / 11035890909445609}$

To link to this article: http://dx.doi.org/10.1080/11035890909445609

曲 Published online: 06 Jan 2010.

Submit your article to this journal $₫$

Џ Article views: 3

Q View related articles $\sqsubset$ 
Om olika jordarters olika förmåga att upplösa benmjölet. Af

E. O. Arenander.

För många år sedan påvisade Gunvar Axderssox, ${ }^{1}$ hurusom den egendomliga geografiska fördelningen af däggdjurs. fynd $i$ våra mossar måste anses. stå $i$ samband med förekomsten af kalkrika jordarter, ur hvilka tillräckliga mängder kalk utlakas för att kunna neutralisera humussyrorna i torf. bäcken, hvadan dessa ej tillgripa den fosforsyrade kalken i de ben, som tilläfrentyrs blifva inlagrade $i$ mossarna.

Alldenstund nyare undersökningar på agrikulturteknikens område stöder denna förklaring af att Skånes, Ölands och Gotlands mossar äro rika på däggdjursben, medan sådana synas alldeles saknas i Smảland $\mathrm{m}$. Hl. landskap, har jag sammanfattat resultaten af nyssnämnda undersökningar, hvilka torde ha ett visst intresse für paleontologerna, hvadan de hăr meddelas.

Det ur ett från slutet af 1700-talet från England spridt bruk att sönderstampa eller söndernala ben till mer eller mindre fint benmjöl, som anvïindes till gödning på åkrar, och benmjölet var dürför det första fosforsyrehaltiga bigödningsämne som användes. Många prisade benmjölets hastiga och tydliga inverkan pâ skördarna; andra ảter voro mindre entusiastiska

' Studicr öfrer Finlands torfmossar och fossila krartärflora. Ikull. Comn. Géol. de Finlande, N:o 8, 1894. 
Bd 31. H. 5.] JORDARTERS FÖRMI̊A ATT UPPLÖSA BENMJÖLET. 399

i sina omdömen och framböllo, att det verkade mycket långsamt. De praktiska männen vore emellertid ense om, att det var ett kraftigt verkande fosforsyre-gödselmedel.

Då framkommo på 1890-talet två berömda forskare i Tyskland, Wagner (Darmstadt) och Mareker. (Halle) med det påståendet, att benmjölets gödsclvärde var mycket öfverdrifvet, $i$ det att dess fosforsyra verkade mycket svagare och långsammare i förhållande till andra fosforsyrerika fodermedel än man förr trott.

De hänrisade på försök, som de gjort, och mot hvilkas anordning ingenting var att anmärlia.

Det måste sålunda uppenbarligen finnas några omständigheter, som inverkade pá dessa resultat, som stredo mot den praktiska erfarenheten, men hvilka omständigheter ej dã roro kända. Det var ju ganska tydligt, att olika resultat ej kunde erhållas af benmjölet genom andra omstandigheter än att bemijölets fosforsyrade liall: upplöstes olika lingsant under. olitia förhållanden.

KellNer påpekade då några försök, som han gjort $\mathrm{i}$ Japan och som antydde, att frânvaro eller närvaro af kalk $i$ jorden rar orsak härtill. Dessa försök afrisades emellertid med att de gällde för Japan men ej för Europa. KeLLNer och BötTCIER (Möckern) anstälde då en del nya försök och publicerade under år 1900 resultaten af dessa, som bidrogo till att gifva förklaring offer, hvarför benmjöls fosforsyra i vissa fall upplöstes sà längsamt. De började sin redogörelse (se Jahres-Bericht iiber die Erfahrungen und Fortschritte auf dem Gesamtgcbiete der Landwirtschaft 15 Jahr. 1900. Braunschweig 1901, S. 283) med att framhålla, att SWAGNER (Darmstadt) och MareKer (Halle) i motsats till KeLLNERS redan i Japan utförda försök konstaterat blott en ringa verkan af benmjölsfosforsyran. KeLLìer påvisade nu, att såväl Wagner som Mereker vid sina vegetationsförsök anrändt jord, dels af naturen kalkrik och dels rikligt kalkad. sDå nu kalken lätt förenar sig med humus och andra lösande agentier, så var det att för27-09221. G. G.F. 1909. 
moda, att jordens upplösningsförmåga vid dessa försök antingen ursprungligen var ringa eller genom kalkmängden blifvit förlamad.s För att experimentellt pröfva denna uppfattnings riktighet, så hade de nämnda författarne sedan 3 ảr tillbaka utför't diverse försök pả det sütt, att benmjölet an. vändes dels utan och dels tillsammans med kalk. De jordslag, som användes till försöken, roro ingalunda shumusrikas, utan höllo blott 2,12, 2,38 och 1,91 \% humus, procenttal som kom. ma mycket nära medeltalen för vanlig åkerjord. Af' kolsyrad kalk funnos endast spår i samtliga försöksjordarna. Efter mindre förberedande försök, som alla gingo i samma riktning, anställdes förliden höst försök i större omfattande skala. En lätt lerjord, med 1,91 \% vattenfri humus jämte $0,02 \%$ kol syra, användes och visade sig hafva stort behof af fosforsyra.

Vid ssamtliga försölicn med benmiöl inträddle en stor sliördeminslining saisom en foljd af samtidig lalligödsling. I genomsnitt af försölien med enkel fosforsyregifva sänlites verlian af benmjölsforsyran genom lialligüdsling till $33 \%$ á, allsci med $67 \%$, om man sätter den öliade sliörden $i$ de icke lialliade lä̈rlen lika med 100».

Han tillägger därefter, att resultaten af MrenErers och WagNens försök hafva därför icke en allmängiltighet, som man velat tillskrifva dem, utan gäller endast kalkrik eller nykalkad jord, men sicke för flertalet af alierjordarter, i hvilla den kolsyrade kalken iclic är en mera allmänt föreliommande jordbestindstel.s

sPả hvilket sätt benmjölsfosforsyrans verksamhet nedsăttes genom kalken, kan för närvarande icke med bestämdhet afgöras.» Han förmodar dock, att humusïmnena liksom den vattenlösliga kiselsyran, den nybildade salpetersyran och kol syran, hrilkas bildning sammanhänger med humussönderdelningen, hürvid spela en roll, då alla dessa lösande ämnen däremot, när kalk är närvarande i form af hydrat eller karbonat, lätt förena sig med denna och sảlunda neutraliseras. 
Bd 31. Ul. 5.] JORDARTERS FÖRUL̊̊a ATT UFPLÖSA BENMJÖLET. 401 Möjligen kunna äfven jordbakterier, som hämmas genom kalknärvaron, inverka på benmjölsfosforsyrans lösning.

Det är hvad man för närvarande ret om lialliens hämmande inverkan pa benmjölets upplösning. Senare försök af sâvall samma forskare som andra hafva ytterligare bekräftat, huru jordens kallihalt hindrar benmjölets upplösning.

Af dessa anför jag blott följande försök af samma personer, Kellayer och BötTcher, hvilka utfördes med hafre för att utröna olika fosfats gödselverkan. Redogörelsen därför är âr 1902 publicerad i Chemiker-Zeitung och i Jahres-Bericht über die Erfahrungen und Fortschritte der Landwirtschaft, Braunschweig 1903, S. 86 .

„Den ökade skörden $\mathrm{i}$ torrtubstans utöfver ogödsladt (ntan fosforsyra) utgjorde för hvarje gram fosforsyra:s

\begin{tabular}{|c|c|c|c|c|}
\hline & \multicolumn{2}{|c|}{ 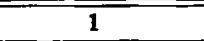 } & \multicolumn{2}{|c|}{2} \\
\hline & \multicolumn{2}{|c|}{ Skörd. } & \multicolumn{2}{|c|}{$\begin{array}{l}\text { Skoordeokning då } \\
\text { utan kalk }=100 \text {. }\end{array}$} \\
\hline & $\begin{array}{l}\text { Utan } \\
\text { kalk. }\end{array}$ & $\begin{array}{l}\text { IIed } \\
\text { kalk. }\end{array}$ & $\begin{array}{l}\text { Utan } \\
\text { kalk. }\end{array}$ & $\begin{array}{l}\text { Jled } \\
\text { kalk. }\end{array}$ \\
\hline 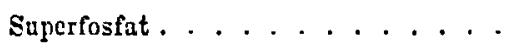 & $169 \cdot 7$ & $150 \cdot 3$ & 100 & 89 \\
\hline Losbos-guano . . . . . . . & $58 \cdot 8$ & $30 \cdot 3$ & 35 & 18 \\
\hline Algier-Phosfat $A$. . . & $65 \cdot 5$ & $23 \cdot 3$ & 39 & 14 \\
\hline Râtt indiskt benmjöl . . & $93 \cdot 3$ & $56 \cdot 2$ & ōō & 33 \\
\hline
\end{tabular}

- Genom kallitillskott minskades gölningsterlian af samtliga fosfater, dock mest af råfosfaten och benmjöl, likaså af de båda Peru-guano-sorterna, men minst af superfosfatet (med den lättlösligaste fosforsyran). Blott $i$ de icke med kalk gödslade kürlen hade dürfür fosforsyran nått till full verkans.

Af dessa försök och erfarenheter, sedla i stort och för långa tidrymder, synes man kunna draga den slutsatsen, att 
[Maj 1909.

man endast $i$ kalkrik jord och mossar $i$ kalkrika trakter kan vänta att finna ben af djur, som kommit ned i mossarna. Detta förklarar sannolikt, hvarför fynden af djurben i Slả. nes kalkrika torfmossar äro rika, medan sñdana ej iro bekanta frân Smâlands kalkfattiga mossar. 